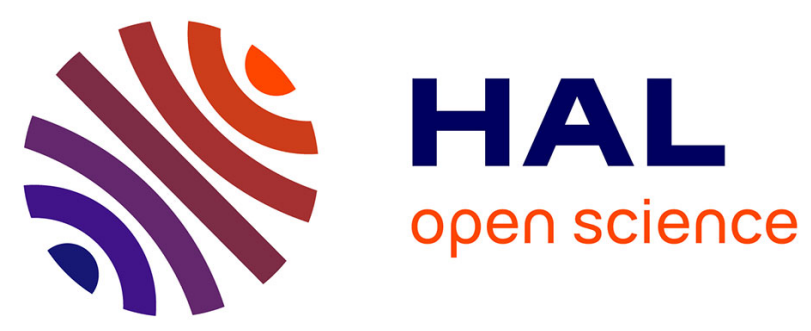

\title{
Semi-automated stereoradiographic upper limb 3D reconstructions using a combined parametric and statistical model: a preliminary study
}

Fréderic Lebailly, Lucas Lima, Alain Clairemidi, Benjamin Aubert, Sandra Guerard, Yasmina Chaïbi, Jacques de Guise, Christian Fontaine, Wafa Skalli

\section{To cite this version:}

Fréderic Lebailly, Lucas Lima, Alain Clairemidi, Benjamin Aubert, Sandra Guerard, et al.. Semiautomated stereoradiographic upper limb 3D reconstructions using a combined parametric and statistical model: a preliminary study. Surgical and Radiologic Anatomy, 2012, 34 (8), pp.757-765. 10.1007/s00276-011-0884-9 . hal-00866977

\section{HAL Id: hal-00866977 https://hal.science/hal-00866977}

Submitted on 30 Sep 2013

HAL is a multi-disciplinary open access archive for the deposit and dissemination of scientific research documents, whether they are published or not. The documents may come from teaching and research institutions in France or abroad, or from public or private research centers.
L'archive ouverte pluridisciplinaire HAL, est destinée au dépôt et à la diffusion de documents scientifiques de niveau recherche, publiés ou non, émanant des établissements d'enseignement et de recherche français ou étrangers, des laboratoires publics ou privés. 


\title{
Semi-automated stereoradiographic upper limb 3D reconstructions using a combined parametric and statistical model: a preliminary study
}

\author{
F. Lebailly $\cdot$ L. V. P. C. Lima A. Clairemidi • \\ B. Aubert · S. Guerard - Y. Chaibi • \\ J. de Guise · C. Fontaine · W. Skalli
}

\begin{abstract}
Purpose Quantitative assessment of 3D clinical indices may be crucial for elbow surgery planning. 3D parametric modeling from bi-planar radiographs was successfully proposed for spine and lower limb clinical investigation as an alternative for CT-scan. The aim of this study was to adapt this method to the upper limb with a preliminary validation.

Methods CT-scan 3D models of humerus, radius and ulna were obtained from 20 cadaveric upper limbs and yielded parametric models made of geometric primitives. Primitives were defined by descriptor parameters (diameters, angles...) and correlations between these descriptors were found. Using these correlations, a semi-automated reconstruction method of humerus using bi-planar radiographs was achieved: a 3D personalized parametric model was built, from which clinical parameters were computed [orientation and projections on bone surface of trochlea sulcus to capitulum (CTS) axis, trochlea sulcus anterior offset and width of distal humeral epiphysis]. This method
\end{abstract}

F. Lebailly · L. V. P. C. Lima ( $ه) \cdot$ A. Clairemidi · B. Aubert · S. Guerard · Y. Chaibi · W. Skalli

Laboratoire de Biomécanique, Arts et Metiers ParisTech,

151 Boulevard de l'Hopital, 75013 Paris, France

e-mail: venancio.lucas.unb@gmail.com

F. Lebailly · A. Clairemidi · C. Fontaine

Service d'orthopédie B, Hôpital Roger Salengro, CHRU de Lille,

Boulevard du Professeur Emile Laine, 59037 Lille cedex, France

Y. Chaibi · J. de Guise

Laboratoire de recherche en Imagerie et Orthopédie,

ETS-CRCHUM, Centre de recherche du CHUM, Pavillon J.A. de Sève, Hôpital Notre-Dame, 1560 rue Sherbrooke Est local Y-1615, Montreal, QC H2L 4M1, Canada was evaluated by accuracy compared to CT-scan and reproducibility.

Results Points-to-surface mean distance was $0.9 \mathrm{~mm}$ $(2 \mathrm{RMS}=2.5 \mathrm{~mm})$. For clinical parameters, mean differences were $0.4-1.9 \mathrm{~mm}$ and from $1.7^{\circ}$ to $2.3^{\circ}$. All parameters except from angle formed by CTS axis and bi-epicondylar axis in transverse plane were reproducible. Reconstruction time was about 5 min.

Conclusions The presented method provides access to morphological upper limb parameters with very low level of radiation. Preliminary in vitro validation for humerus showed that it is fast and accurate enough to be used in clinical daily practice as an alternative to CT-scan for total elbow arthroplasty pre operative evaluation.

Keywords CT-scan - Elbow arthroplasty planning Humerus · Morphological database

\section{Introduction}

Standard radiographs, CT-scan associated or not with an arthrography, and MRI are the usual imaging tools for elbow investigation in clinical daily practice. CT-scan allows 3D imaging; quantitative assessment of 3D clinical indices is also possible [5], but requires a quite lengthy process, which makes it inappropriate for clinical use. Furthermore, CT-scan exposes the patient to a high level of radiation.

Specific methods that achieve 3D parametric models from bi-planar calibrated radiographs could be an alternative. The general principle of these methods is to use data obtained from the bi-planar radiographs to deform a 3D model to achieve a personalized one. The first method developed achieved 3D non-parametric models and required 
identification of numerous anatomical landmarks (points or contours) leading to lengthy process. More recent methods have used parametric models of vertebra [16] and spine [12] made of points and axes. Statistical correlations between these parameters are used to accelerate the process. In this way, spine reconstruction time has been considerably reduced from 2 to even $4 \mathrm{~h}$ down to less than $15 \min$ [12]. These 3D parametric models are used in practice for scoliosis investigation. Such methods have also been developed for pelvis [14] and lower limb [1, 3, 6, 11]. For lower limb modeling, the parametric models are made of 3D geometric "primitive" elements (spheres, ellipses and circles), which are defined by geometric "descriptive" parameters (diameters, angles, distances and coordinates of points).

Upper limb parametric 3D modeling using bi-planar radiographs is a more recent and less advanced development. Berthonnaud et al. [2] used simplified geometric parametric models of scapula, humerus and clavicle obtained from bi-planar X-rays for a kinematic study of the shoulder. Parametric models can be useful for clinical investigation: 3D parametric model may provide relevant data which are difficult to obtain with usual imaging tools or clinical insight such as projected points of flexion-extension elbow axis on bone surface. At the best of our knowledge, there is no such 3D modeling method adapted to clinical practice.

Based on these previous works on spine and lower limbs, this study proposes a combined parametric and statistical modeling method of humerus, radius and ulna and presents a preliminary evaluation for humerus.

\section{Methods}

General principles of the reconstruction method

Upper limb long bones have been modeled as a Simplified Personalized Parametric Model (SPPM) made of 3D elements called geometric primitives such as spheres, circles, ellipses and 3D points. These geometric primitives are described by geometric parameters called descriptors: some descriptors define one geometric primitive (a sphere is defined by its center coordinate and its radius, as well as a circle); while other descriptors define relationships between different geometric primitives (distance between two circle centers, angles between two axis).

The reconstruction process began with the placement of a set of few geometric primitive projections on the bi-planar X-rays. Others were estimated by statistical inferences. A medium-size CT-scan 3D parametric model was deformed to tie in these primitives giving an initial solution of the Morphorealist Parametric Personalized Model (MPPM), which was displayed on the bi-planar $\mathrm{X}$-rays. Manual adjustment achieved the optimal solution of the MPPM. All descriptors could be computed from the MPPM, but only the one chosen for their interest for elbow surgery planning would be.

\section{Coordinate systems}

A local 3D coordinate system was associated to humerus and another one to forearm. This system is detailed in Appendix 1.

\section{Data acquisitions}

Twenty cadaveric embalmed upper limbs (scapulo-humeral disarticulation) provided by the Institute of Anatomy of Lille 2 University (France) were used. Eighteen were paired; the two remaining were the left side of a man, and the right side of a woman. There were eight males and three females. The mean age was 74.6 years (58-84 years).

The upper limbs were fixed to Plexiglas plates in neutral rotation of the arm and in a full extension and supination of the forearm. To obtain this position, the elbow was first positioned at $90^{\circ}$ of flexion, the forearm perpendicular to the plate in the frontal plane: in this way, the arm was in neutral rotation. An antero-posterior screw was placed at the middle of the humeral diaphysis. Then, the forearm was positioned in full extension and supination. A screw was placed through the lateral part of the carpus or second intermetacarpal space. For the first 12 upper limbs, standard metallic screws were used; for the eight others, plastic screws were used to avoid artifacts on radiograph and CT-scan. Two plastic straps passing through holes made into the plates were added: one around the arm, and one around the wrist.

CT-scans of these upper limbs were done in the Musculo-skeletal imaging department of the University hospital of Lille (France). The acquisitions consisted in a single axial helix with scan spacing of $0.4 \mathrm{~mm}$, thickness of $0.6 \mathrm{~mm}$ and resolution of $0.36 \times 0.36 \mathrm{~mm}, 120 \mathrm{kVp}$ $\left(\right.$ SIEMENS ${ }^{\circledR}$, Somatom Sensation $64^{\circledR}$ ). A standard bone reconstruction filter was used.

Bi-planar $90^{\circ}$ self-calibrated radiographs provided by $\operatorname{EOS}^{\circledR}$ (EOS imaging system, Paris, France) of the 20 upper limbs fixed to the plates in the same position were obtained $(90 \mathrm{kVp}, 200 \mathrm{~mA}, 0.186 \mathrm{~mm} /$ pixel, resolution of $0.186 \times 0.186 \mathrm{~mm}$ ). Additional details about image quality and entrance dose for the patient were evaluated elsewhere $[8,9]$.

Data processing

Data obtained from CT-scan

Surface 3D models of each humerus, radius and ulna were obtained from CT-scan slices by segmentation using 
AVIZO 5. ${ }^{\circledR}$ software (Mercury Computer System, Berlin, Germany ${ }^{\circledR}$ ). Each bone was segmented separately using different $\mathrm{AVIZO}^{\circledR}$ tools. First the "magic wand segmentation tool" was used, it allowed selecting the largest connected area that contained all voxels with gray values lying inside a user-defined range. This range was chosen to select areas that formed a volume as close as possible of the whole bone volume. "Grow" or "shrink selection filters" were used. These filters performed a morphological dilatation or erosion of the current selection. Manual adjustments slice-by-slice, using the "brush segmentation tool" were necessary especially on epiphysis and around the screws to refine the selection. At last, "fill" selection filter was used to obtain a full volume. "Label filters" such as "Remove Island" and "fill holes" were used to perform the last adjustments. From the segmented volume, a triangular surface grid was extracted and simplified using AVIZO "surface simplification editor".

For each model, we extracted points from anatomical regions using a specific software developed in our laboratory $(\mathrm{C}++)$ : it achieved "regionalized models" made of 15 regions for humerus, 11 for radius and 11 for ulna (Fig. 1).

For each region, a simple geometric least-squares element, corresponding to the geometric primitives of the SPPM, was fitted using a MATLAB ${ }^{\circledR}$ (version 7.0, The
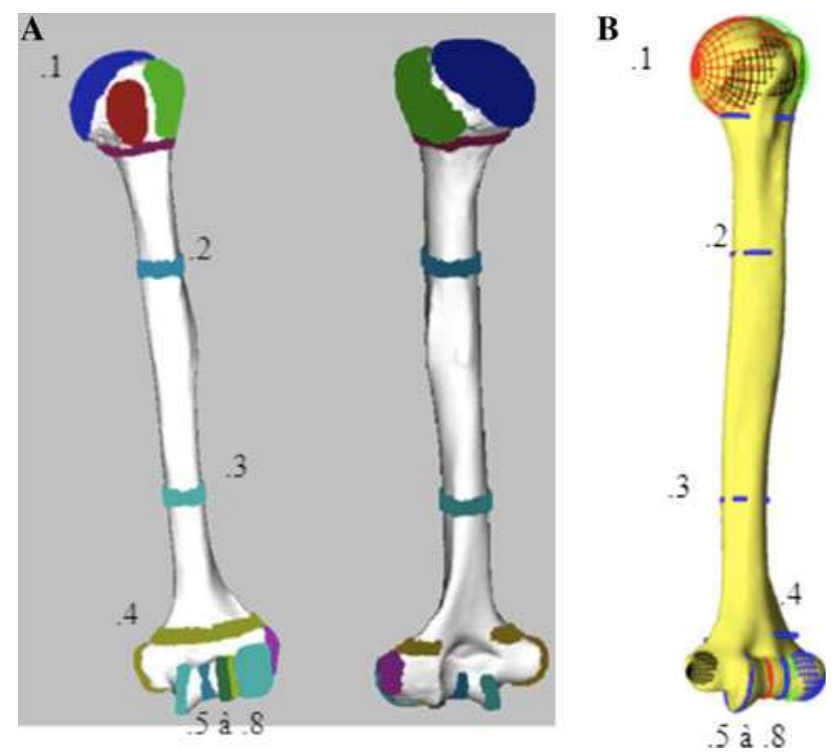

Fig. 1 CT-scan humerus 3D parametric model. a Regions (major regions described below); b corresponding geometric least square elements. 1 Humeral head region and corresponding least square sphere; 2, 3 superior and inferior diaphysis regions and corresponding least square circles; 4 distal metaphysis region and corresponding least square ellipse; 5, 6, 7 medial trochlea, trochlea sulcus and lateral trochlea regions and corresponding least square circles; 8 capitulum region and corresponding least square sphere. For these elements, descriptors parameters were diameter and center coordinate for spheres and circles and major axis, minor axis and center coordinate for ellipses
MathWorks ${ }^{\circledR}$, Natick, Massachusetts, USA) application (Fig. 1). This built up a large database of 40 primitives and 296 descriptors of these upper limb long bones.

This database was used for two different purposes. It was the gold standard for accuracy evaluation of the humerus-constructed models. It was also used to lead a correlation analysis between descriptors based on multilinear regression to assess parameters that could be used as "predictors" of other descriptive parameters.

A leave-one-out procedure was performed to check if there was no statistical bias introduced by the use of the same database for correlation analysis and evaluation. This procedure is detailed in Appendix 2.

Among the descriptors of humerus, "clinical parameters" were chosen for their potential interest for elbow prosthetic replacement planning (Fig. 2): (1) the distance between the capitulum center and the medial trochlea center; (2) the distance between medial trochlea center and lateral trochlea center; (3) the angles between the axis formed by the center of the capitulum and the center of the trochlea sulcus (CTS axis) and the long axis of the diaphysis in the frontal plane; (4) the angle between CTS axis and the one formed by the barycenter of lateral epicondyle and the center of the medial epicondyle sphere (EC axis or biepicondylar axis) in both frontal and in transverse planes; (5) the coordinates of the projected points of the CTS axis on the lateral and medial surfaces of the 3D model; (6) the distance between trochlea sulcus center and humeral diaphysis long axis (trochlea sulcus anterior offset).

\section{Data obtained from bi-planar radiographs}

A parametric 3D modeling method of humerus using bi-planar radiographs was achieved. The reconstruction process used 2D projections of 3D geometric primitives and 3D parametric models, which were displayed on bi-planar X-rays using specific software $(\mathrm{C}++)$. Four successive steps were needed (Fig. 3):

Step 1: The operator initialized the process by adjusting humeral head and capitulum spheres projections.

Steps 2 and 3: "Medial trochlea extremity point" position (step 2), and circles of medial trochlea, lateral trochlea and trochlea sulcus (step 3) were statistically estimated. If necessary, they were adjusted by the operator. A SPPM was obtained.

Step 4: From the SPPM descriptors, one "mediumsized" humerus 3D parametric CT-scan model was deformed using an as-rigid-as-possible deformation method based on Moving Least Squares (MLS) approach [7] providing an initial solution for the MPPM. Projections of this model were displayed on bi-planar X-rays. 
Fig. 2 Clinical parameters $a$ CTS axis/diaphysis axis angle (frontal plane), $b$ CTS axis/EC axis angle (frontal plane), $c$ CTS axis/EC axis angle (transverse plane), $A$ projected point of CTS axis on medial bone surface, $B$ projected point of CTS axis on lateral bone surface
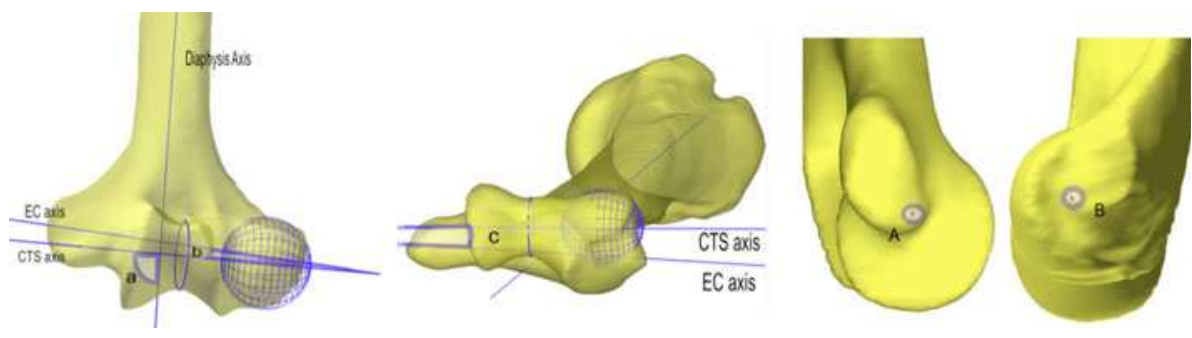
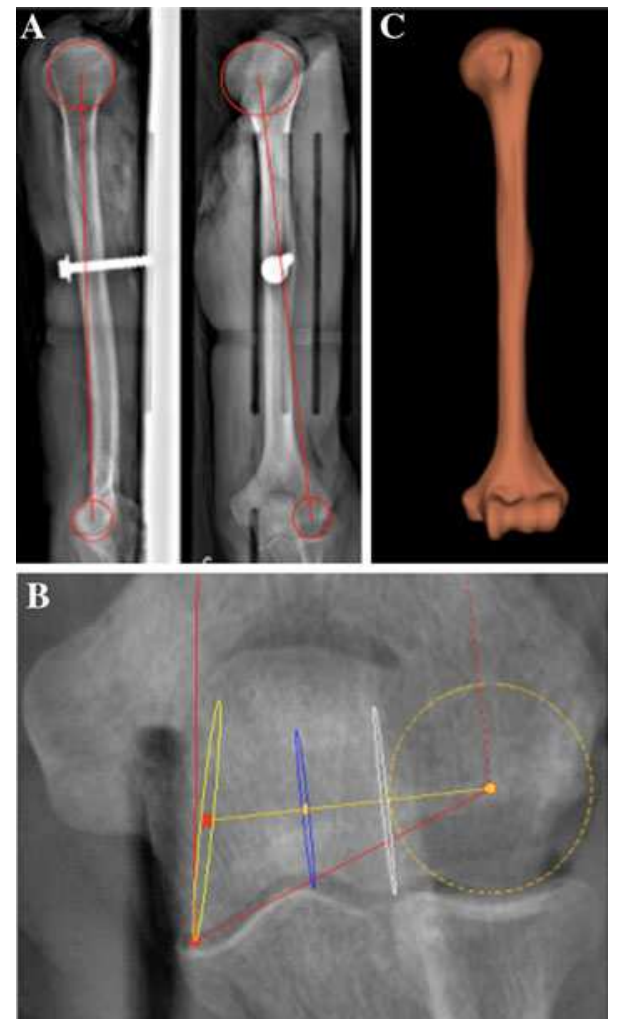

Fig. 3 Reconstruction process a placement of first two geometric primitives at step 1(humeral head sphere and capitulum sphere), b adjustment of geometric primitives at step 3 (capitulum sphere and trochlea circles), c MPPM obtained

If the projection of the model obtained were not well fitted to the radiographic bone contours, the operator can deform the MPPM using MLS handle points [7]. The clinical parameters described above were computed from the MPPM.

\section{Accuracy evaluation}

A single operator (an orthopedic surgery resident) applied the presented method on 19 upper limbs stereoradiographs out of the 20: the stereoradiographs of the "medium-sized" upper limb used at step 4 of the process was ruled out. Each one of humerus model obtained was compared to the corresponding reference $3 \mathrm{D}$ model obtained from CT-scan considering two different criteria:
Table 1 Correlations founded with their standard error of the estimate (SEE) in $\mathrm{mm}$

\begin{tabular}{lll}
\hline Dependent variables & Explaining variables & SEE $(\mathrm{mm})$ \\
\hline h_L_cap_TM & h_head_Diam & 1.337 \\
h_L_head_TM & h_L_head_cap h_head_Diam & 1.587 \\
h_L_cap_sulcus & h_L_cap-TM & 0.593 \\
h_L_head_sulcus & h_L_head_cap & 0.881 \\
h_troc_sulcus_Diam & h_L_head_TM & 0.121 \\
h_L_troc_med_capi & h_L_cap_TM & 0.362 \\
h_troc_med_Diam & h_head_Diam & 0.263 \\
h_L_troc & h_head_Diam & 0.828 \\
h_troc_lat_Diam & h_cap_Diam & 0.242 \\
\hline
\end{tabular}

$h$ Humerus, $L$ distance or size, Diam diameter of sphere or circle fitted, head humerus head, TM extreme medial inferior point of trochlea, cap capitulum, troc whole trochlea, troc_med medial trochlea, troc_lat lateral trochlea, sulcus trochlea sulcus

h_L_head_cap: distance between center of humerus head and capitulum center; h_troc_lat_Diam: diameter of lateral circle fitted in trochlea

1. Points-to-surface distances between reconstruction and reference surface obtained from CT-scan were analyzed, on the whole surface and on regions that influenced clinical parameters. Mean and maximal values and 2 Root Mean Square (RMS) corresponding to confidence interval of $95 \%$ are presented in Table 1 .

2. Difference between clinical parameters determined on reconstructions and on reference objects obtained from CT-scan. Mean and maximal differences and 2 RMS are presented in Table 2.

\section{Reproducibility evaluation}

In an intra-rater study, six bi-planar radiographs of six paired upper limbs were reconstructed three times using the presented method by the same operator (an orthopedic surgery resident). In an inter-rater study, these six bi-planar radiographs were reconstructed three times by two operators (an orthopedic surgery resident and a biomechanics engineer).

For both of these studies, using a MATLAB ${ }^{\circledR}$ (version 7.0, The MathWorks ${ }^{\circledR}$, Natick, Massachusetts, USA) application, the mean values of each clinical parameter 
Table 2 Accuracy evaluation: 3D model points-to-surface distances (mm)

\begin{tabular}{llllllllll}
\hline & All & $\begin{array}{l}\text { Medial } \\
\text { trochlea }\end{array}$ & $\begin{array}{l}\text { Lateral } \\
\text { trochlea }\end{array}$ & $\begin{array}{l}\text { Trochlea } \\
\text { sulcus }\end{array}$ & Capitulum & $\begin{array}{l}\text { Lateral } \\
\text { epicondyle }\end{array}$ & $\begin{array}{l}\text { Medial } \\
\text { epicondyle }\end{array}$ & $\begin{array}{l}\text { Inferior } \\
\text { diaphysis }\end{array}$ & $\begin{array}{l}\text { Superior } \\
\text { diaphysis }\end{array}$ \\
\hline Mean values & 0.9 & 0.9 & 0.6 & 0.6 & 0.8 & 0.7 & 0.9 & 0.9 & 0.6 \\
2 RMS & 2.5 & 2.4 & 1.6 & 1.6 & 2.0 & 1.8 & 2.3 & 2.3 & 1.6 \\
$\begin{array}{l}\text { Maximal } \\
\text { values }\end{array}$ & 6.7 & 5.2 & 2.4 & 3.6 & 3.8 & 3.7 & 4.4 & 3.6 & 3.3 \\
\hline
\end{tabular}

Number of points All: 10, 000, medial trochlea: 150, lateral trochlea: 75, troclea sulcus: 128 , lateral epicondyle: 138, medial epicondyle: 153 , inferior diaphysis: 59, superior diaphysis: 66

were calculated: they were used as a reference for uncertainty estimation. The interval of confidence was estimated by the Root Mean Square of Standard Deviation [RMS $(\mathrm{sd})]$. Friedman test was used to determine if the reconstruction samples were comparable $(p$ value $>0.05)$. Shapiro-Wilk's test was used to determine if the values seemed to follow a normal distribution $(p$ value $>0.05$ ). When the reconstruction samples were comparable and followed a normal distribution, the approach allowed estimating a $95 \%$ confidence interval for the precision given by $\pm 2 \mathrm{RMS}_{\mathrm{SD}}$.

\section{Reconstruction time}

The operators evaluated reconstruction time during these evaluations.

\section{Results}

Regressions results

The dependent variables with their respective explaining variables implemented in the proposed reconstruction application are presented in Table 1 with their Standard Error of the Estimate (SEE).

The maximum difference found in the leave-one-out procedure was smaller than $1 \mathrm{~mm}$ for all descriptive parameters. Regarding the magnitude of these results compared to CT-scan accuracy, we considered that there was no statistical bias introduced by the use of the same database for correlation analysis and evaluation.

\section{Accuracy evaluation}

Points-to-surface distances (Table 2) mean value for the whole surface was $0.9 \mathrm{~mm} \quad(2 \mathrm{RMS}=2.5 \mathrm{~mm}$; $\max$. value $=6.7 \mathrm{~mm}$ ). For regions that influenced the computation of clinical parameters points-to-surface distances were even smaller: from $0.6 \mathrm{~mm} \quad(2 \mathrm{RMS}=1.6 \mathrm{~mm}$; $\max$. value $=3.6 \mathrm{~mm})$ for trochlea sulcus to $0.9 \mathrm{~mm}(2 \mathrm{RMS}=$ $2.4 \mathrm{~mm}$, max. value $=5.2 \mathrm{~mm}$ ) for medial trochlea.
The mean differences for epiphysis dimensions compared to reference objects were lower than $1 \mathrm{~mm}$ (Table 3). The mean difference between CTS axis/diaphysis axis in the frontal plane was $1.7^{\circ}\left(2 \mathrm{RMS}=4.1^{\circ}\right.$; max. value $=$ $3.9^{\circ}$ ), whereas the mean difference between CTS axis/EC axis angles was higher: $2.0^{\circ}\left(2 \mathrm{RMS}=4.7^{\circ}\right.$; max. value $=$ $\left.4.3^{\circ}\right)$ in the frontal plane and $2.3^{\circ}\left(2 \mathrm{RMS}=7.2^{\circ}\right.$; max. value $=10.3^{\circ}$ ) in the transverse plane; likewise, the mean difference for projected point on lateral surface $\mathrm{z}$-axis coordinates was $2.4 \mathrm{~mm}(2 \mathrm{RMS}=6.1 \mathrm{~mm}$; max. values $=8.5 \mathrm{~mm}$ ).

Reproducibility evaluation

All samples were not normally distributed (Table 4). Results obtained from the Friedman's test encourage keeping the hypothesis that the value samples are comparable, except for CTS axis/EP axis angle in transverse plane. It ensures that this method is intra- and inter-rater reproducible for all clinical measurements except CTS axis/EP axis angle in transverse plane.

\section{Reconstruction time}

For the two evaluators, at the top of the learning curve, the reconstruction time was around $5 \mathrm{~min}$.

\section{Discussion}

3D parametric model of bones can be obtained using CTscan but it requires a lengthy process non optimal for clinical daily practice. Brownhill et al. [5] used humerus CT-scan 3D models for clinical research. They obtained a 3D surface by CT-scan slices segmentation. They extracted points from each anatomical region of the surface and fitted $3 \mathrm{D}$ least square geometric elements corresponding to these regions. It achieves a 3D parametric model. It allows computation of geometric parameters. That is the kind of process that we also used to build up our database. For the humerus, it took at least $1 \mathrm{~h}$ for segmentation and $1 \mathrm{~h}$ for selecting regions; then computation remains to be done. 
Table 3 Accuracy evaluation difference between clinical parameters obtained with our method and from reference object

\begin{tabular}{|c|c|c|c|c|c|c|c|c|c|c|c|c|}
\hline & \multicolumn{6}{|c|}{$\begin{array}{l}\text { CTS axis projected } \\
\text { points }(\mathrm{mm})\end{array}$} & \multicolumn{3}{|c|}{ Angles $\left({ }^{\circ}\right)$} & \multirow{3}{*}{$\begin{array}{l}\text { Trochlea sulcus center } \\
\text { diaphysis axis anterior } \\
\text { offset }(\mathrm{mm})\end{array}$} & \multicolumn{2}{|c|}{$\begin{array}{l}\text { Distal epiphysis widths } \\
(\mathrm{mm})\end{array}$} \\
\hline & \multicolumn{3}{|c|}{$\begin{array}{l}\text { Medial } \\
\text { surface }\end{array}$} & \multicolumn{3}{|c|}{$\begin{array}{l}\text { Lateral } \\
\text { surface }\end{array}$} & \multicolumn{2}{|c|}{ CTS axis/EC axis } & \multirow{2}{*}{$\begin{array}{l}\text { CTS axis/ } \\
\text { diaphysis axis } \\
\text { Frontal }\end{array}$} & & \multirow[t]{2}{*}{$\begin{array}{l}\text { Medial trochlea/ } \\
\text { capitulum }\end{array}$} & \multirow[t]{2}{*}{ Trochlea } \\
\hline & $X$ & $Y$ & $Z$ & $X$ & $Y$ & $Z$ & Frontal & Transversal & & & & \\
\hline Mean value & 0.4 & 0.8 & 1.3 & 0.3 & 0.4 & 2.4 & 2.0 & 2.3 & 1.7 & 1.9 & 1.9 & 0.8 \\
\hline 2 RMS & 1.0 & 2.0 & 3.0 & 0.6 & 1.1 & 6.1 & 4.7 & 7.2 & 4.1 & 2.6 & 2.7 & 2.0 \\
\hline Maximal value & 1.0 & 2.0 & 2.6 & 0.6 & 1.4 & 8.5 & 4.3 & 10.3 & 3.9 & 5.6 & 3.8 & 2.0 \\
\hline
\end{tabular}

Table 4 Reproducibility: inter-rater study

\begin{tabular}{|c|c|c|c|c|c|c|c|c|c|c|c|c|}
\hline \multirow[t]{3}{*}{ Inter-raters } & \multicolumn{6}{|c|}{ CTS axis projected points $(\mathrm{mm})$} & \multicolumn{3}{|c|}{ Angles $\left({ }^{\circ}\right)$} & \multirow{3}{*}{$\begin{array}{l}\text { Trochlea sulcus } \\
\text { center diaphysis axis } \\
\text { anterior offset (mm) }\end{array}$} & \multicolumn{2}{|c|}{$\begin{array}{l}\text { Distal epiphysis } \\
\text { widths }(\mathrm{mm})\end{array}$} \\
\hline & \multicolumn{3}{|c|}{ Medial surface } & \multicolumn{3}{|c|}{ Lateral surface } & \multicolumn{2}{|c|}{ CTS axis/EC axis } & \multirow{2}{*}{$\begin{array}{l}\text { CTS axis/ } \\
\text { diaphysis } \\
\text { axis } \\
\text { Frontal }\end{array}$} & & \multirow{2}{*}{$\begin{array}{l}\text { Medial } \\
\text { trochlea/ } \\
\text { capitulum }\end{array}$} & \multirow[t]{2}{*}{ Trochlea } \\
\hline & $X$ & $Y$ & $Z$ & $X$ & $Y$ & $Z$ & Frontal & Transversal & & & & \\
\hline Mean value & 0.1 & 0.4 & 0.6 & 0.2 & 0.3 & 0.8 & 0.7 & 0.5 & 1.2 & 0.8 & 0.4 & 0.4 \\
\hline 2 RMS (sd) ${ }^{\mathrm{a}}$ & 0.3 & 0.7 & 1.0 & 0.2 & 0.3 & 1.1 & 1.4 & 0.4 & 1.9 & 1.6 & 0.9 & 0.6 \\
\hline Maximal value & 0.5 & 1.7 & 1.7 & 0.6 & 1.1 & 2.9 & 2.6 & 1.4 & 4.7 & 3.2 & 1.5 & 1.4 \\
\hline Friedman $\mathrm{p}$ & 0.76 & 0.86 & 0.34 & 0.24 & 0.57 & 0.91 & 0.83 & $\mathbf{0 . 0 3}$ & 0.74 & 0.37 & 0.88 & 0.26 \\
\hline Reproductible & Yes & Yes & Yes & Yes & Yes & Yes & Yes & No & Yes & Yes & Yes & Yes \\
\hline Shapiro-Wilk p & 0.14 & 0.03 & 0.36 & 0.20 & 0.00 & 0.06 & 0.00 & 0.01 & 0.35 & 0.24 & 0.32 & $\mathbf{0 . 0 3}$ \\
\hline Normal distribution & Yes & No & Yes & Yes & No & Yes & No & No & Yes & Yes & Yes & No \\
\hline
\end{tabular}

Bold values indicate $p<0.05$

${ }^{\mathrm{a}} \mathrm{RMS}_{\mathrm{SD}}=\sqrt{\sum_{j=1}^{m} \frac{\sum_{i=1}^{n}\left(\bar{\alpha}_{j}-\alpha_{i j}\right)^{2} / n-1}{m}}$

$n$ : number of reconstruction of the same humerus by the two operators; $m$ : number of specimen; $\bar{\alpha}_{j}$ : mean value of different reconstructions of the same humerus by the same operator

On the contrary, 3D models using bi-planar radiographs provided by $\mathrm{EOS}^{\circledR}$ can be obtained in a short delay: 3D modeling method developed for spine achieves accurate models in less than $15 \mathrm{~min}$ [12]. Furthermore, they require exposure to very low level of radiation $[8,9]$. For these reasons, these methods appeared to be adapted for clinical applications. Spine modeling using stereoradiographs is already used for scoliosis preoperative investigation and postoperative follow up.

The aim of this study was to develop such a method, which could be used for elbow surgery planning in the future. The specifications were: accuracy, reproducibility, semi-automation and short reconstruction time.

The method has been based on the previous work on lower limb reconstruction [6]. The basis of the method are: (1) to adjust 3D few geometric primitives projections on the radiographic bone contours; (2) to estimate some others primitives using correlations to obtain a SPPM; (3) to deform a parametric model from this primitives to get a initial solution for MPPM; (4) to get the optimal solution for MPPM using fine manual adjustment. The process is considered 'semi-automated' as far as initial solutions at each step are given by statistical inferences and manually adjusted if the model obtained were not well fitted to the radiographic bone contours.

This process lasted approximately $5 \mathrm{~min}$, which is adapted to clinical application. Points-to-surface mean distance is $0.9 \mathrm{~mm} \quad(2 \mathrm{RMS}=2.5 \mathrm{~mm}$; max. value $=$ $6.7 \mathrm{~mm}$ ); for the regions of particular interest such as trochlea circles and capitulum, distances are even smaller, up to $0.6 \mathrm{~mm}(2 \mathrm{RMS}=1.6 \mathrm{~mm}$, max. value $=3.6 \mathrm{~mm})$ for trochlea sulcus. For comparison, CT-scan 3D models resolution is $1.0 \mathrm{~mm}$. Humbert et al. [12] obtained for spine reconstruction a point-to-surface mean value of $1.0 \mathrm{~mm}$ $(2 \mathrm{RMS}=2.7 \mathrm{~mm})$.

These results appear to be accurate and fast enough for clinical application. The difficulties are related to visibility 
of the anatomical landmarks on the X-rays. The current preliminary study focused on in vitro specimens to assess the feasibility of the 3D reconstruction. In vivo assessment is in progress.

The clinical parameters were chosen for their importance for total elbow replacement planning. Position, orientation and projections on bone surface of CTS axis were chosen because it can be considered as an acceptable approximation of flexion-extension elbow axis $[4,5,10$, 13, 15, 18]. Flexion-extension axis has to be restored by a total elbow replacement to avoid early loosening [17]. It is a very important parameter, but it remains difficult to evaluate pre- and per-operatively, particularly in the transverse plane: in practice, it is to be evaluated peroperatively by surgeon insight. 3D models could help to estimate it: Brownhill et al. [4] compared positions of projected points of CTS axis on bone surface selected by 3 surgeons and recorded with an electromagnetic device to the one obtained from a CT-scan 3D model. They concluded that 3D models could allow a more accurate selection of flexion extension axis.

In this study, EC axis was used as a reference to define CTS axis. It appears to be difficult to evaluate: orientation in the transverse plane of both epicondyles was difficult to control because of a lack of radiographic landmarks. It is possible that rotation errors in the transverse plane lead to small points-to-surface distances (accuracy shapes for lateral and medial epicondyles are good) but influence the orientation of EC axis. This could explain higher mean differences for CTS axis/EC axis angle in the frontal plane $\left(2.0^{\circ}\right.$ with $\left.2 \mathrm{RMS}=4.7^{\circ}\right)$ and in the transverse plane $\left(2.3^{\circ}\right.$ with 2 RMS $=7.2^{\circ}$ ) and for coordinate on $\mathrm{z}$-axis of the projected point of CTS axis on lateral bone surface $(2.42 \mathrm{~mm}$ with $2 \mathrm{RMS}=6.11 \mathrm{~mm})$. This could also explain the inter-raters non-reproducibility of CTS axis/EC axis angle in the transverse plane. Evaluation of epicondyles rotation in the transverse plane could be improved using statistic correlations. Another reference could also be used to define CTS axis orientation, which is the relevant data.

Indeed, evaluation of CTS axis in reference to diaphysis axis is better: mean difference is $1.7^{\circ}\left(2 \mathrm{RMS}=4.1^{\circ}\right)$. This remaining difference can be explained by the small size of trochlea sulcus, capitulum and distance between trochlea sulcus and capitulum: even a small positioning error will lead to larger variation of CTS axis orientation. Image processing device in progress and a fully extended use of statistical correlations will surely improve the accuracy of the method.

In clinical daily practice, flexion-extension elbow axis is generally estimated by surgeon insight. We did not compare estimation of flexion-extension elbow axis obtained with the proposed method to surgeon estimation.
Brownhill et al. [4] found that surgeon accuracy for selecting projected points on bone surface without any device was $3.5 \mathrm{~mm}(\mathrm{SD}=1.8 \mathrm{~mm})$ in the proximal-distal direction and $4.5 \mathrm{~mm}(\mathrm{SD}=2.1 \mathrm{~mm})$ in the anteriorposterior directions for the lateral surface and $4.0 \mathrm{~mm}$ $(\mathrm{SD}=1.3 \mathrm{~mm})$ and $3.3 \mathrm{~mm}(\mathrm{SD}=1.5 \mathrm{~mm})$ for the medial surface. These results cannot be directly compared to those obtained with the proposed method because the reference used is different. Nevertheless, mean differences with reference object for coordinates of projected points of CTS axis on bone surface obtained with the proposed method are all inferior to $1 \mathrm{~mm}$ except for coordinate on $\mathrm{z}$-axis of the projected point on lateral bone surface $(2.4 \mathrm{~mm} ; 2 \mathrm{RMS}=6.1 \mathrm{~mm})$, which remains inferior to $3 \mathrm{~mm}$. Considering these values, it seems that the proposed method could help surgeon selecting flexion-extension elbow axis to perform a total elbow replacement.

A further application using this method could also be useful for implant sizing: distance between lateral and medial trochlea and distance between medial trochlea and capitulum center are very well evaluated, respectively $1.0 \mathrm{~mm}$ $(2 \mathrm{RMS}=2.3 \mathrm{~mm})$ and $0.7 \mathrm{~mm}(2 \mathrm{RMS}=2.0 \mathrm{~mm})$. In the same way, trochlea sulcus anterior offset, which evaluates position of diaphysis axis relative to humeral distal epiphysis, could be useful intra-operatively to help positioning the implant stem.

The major interest of this method is that all these 3D clinical indices are represented on a 3D model. Indeed, a surgeon performing a total elbow surgery exposes partially upper limb long bones around elbow: the representation of the clinical indices on 3D models provides anatomical landmarks that the surgeon can directly point on bone surface preoperatively. It is particularly true for flexionextension elbow axis and its projections on bone surface.

\section{Conclusion}

This preliminary study assesses the feasibility of semiautomated upper limb 3D reconstructions from bi-planar radiographs using a combined parametric and statistical model. It is fast and accurate enough to be used for clinical applications. This reconstruction process used global deformation by statistical correlations and manual adjustments. Automatic contour detection based in image processing from this initial solution is in progress. They could substitute manual adjustments as far as the MPPM is already close to the reference object. Also they could achieve more accurate results by local deformation technique to precisely fit the reconstructed model to the X-ray images.

Based on this preliminary in vitro study, full in vivo evaluation is in progress for an application to total elbow surgery planning. 
Acknowledgments We extend our thanks to X. Demondion and to the CT-scan operators of the Musculo-skeletal imaging department of the University Hospital of Lille for their precious help in CT-scan acquisitions; to M. Demeulaere and F. Stevendart from the Institute of Anatomy of Lille 2 University; LBM and LIO-ETS Montréal team (particularly C. Fedelich and T. Cresson).

Conflict of interest This research was conducted with the financial support of MEDICEN competitiveness cluster (SterEOS + project). The authors declare that they have no conflict of interest. The experiments were performed in France and comply to the current laws of this country.

\section{Appendix 1: Coordinate systems}

A local 3D coordinate system was associated to humerus and another one to forearm (Fig. 4). For humerus: let $T$ be the center of trochlea sulcus circle, $H$ be the center of humeral head, $C$ be the center of capitulum sphere; (1) $y$-axis was defined by $\overrightarrow{T H}$; (2) $x$-axis was defined by the vector orthogonal to the plane formed by $C, T$ and $H$ in the postero-anterior sense; (3) $z$-axis was defined by the cross product of $x$ and $y$.

For forearm: let $S$ be the center of the ulnar styloid process sphere, $N$ be the center of the ulnar trochlear notch ridge circle and $R$ the radial styloid process; (1) $y$-axis was defined by $\overrightarrow{S N}$; (2) $x$-axis was defined by the vector orthogonal to the plane formed by $R, S$ and $N$ in the postero-anterior sense; (3) $z$-axis was the cross product of $x$ and $y$. We assumed that the center of the ulnar trochlear
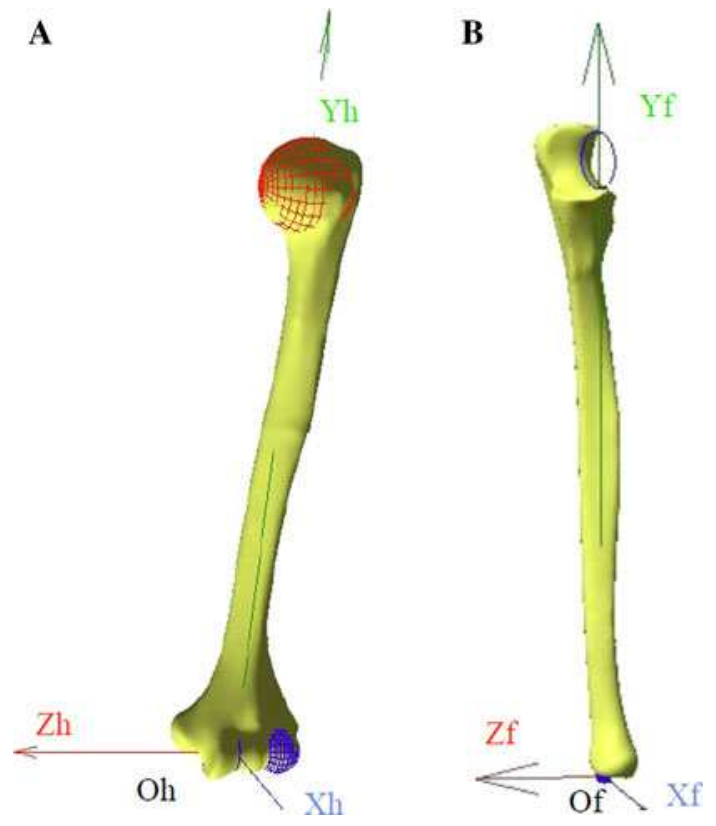

Fig. 4 Frame of references: a humerus, $b$ forearm notch ridge circle was superimposed to the center of the trochlea sulcus circle.

\section{Appendix 2: Leave-one-out method}

Let ${ }^{j}{ }_{\text {regr }}$ [T] be the regression operator obtained from the complete database $[T]$ for the parameter $j$ :

$y_{i j}={ }^{j} \operatorname{regr}_{[T]}\left(x_{i j}\right)$

where $y_{i j}$ is the descriptor obtained from the insertion of the predictor $x_{i j}$, and $i$ refers to the $i$ th humerus removed from the database $T$ to form a reduced one $\left[T-h_{i}\right]$.

In the leave one out procedure the ${ }^{j} \operatorname{regr}_{\left[T-h_{i}\right]}$ is the regression operator obtained from the reduced database $\left[T-h_{i}\right]$.

$y_{k j}^{\prime}={ }^{j} \operatorname{regr}_{\left[T-h_{i}\right]}\left(x_{i j}\right)$

where $y_{i j}^{\prime}$ is the descriptor obtained from the leave one out database.

The difference of those values was evaluated for each parameter $j(j=1 \ldots 10)$ and for each $i$ th humerus from the database $(i=1 \ldots 20)$ by the function $E_{i j}$.

$E_{i j}=\left|y_{i j}-y_{i j}^{\prime}\right|$.

\section{References}

1. Baudoin A, Skalli W, de Guise JA, Mitton D (2008) Parametric subject-specific model for in vivo $3 \mathrm{D}$ reconstruction using biplanar X-rays: application to the upper femoral extremity. Med Biol Eng Comput 46:799-805

2. Berthonnaud E, Herzberg G, Zhao KD, An KN, Dimnet J (2005) Three-dimensional in vivo displacements of the shoulder complex from biplanar radiography. Surg Radiol Anat 27:214-222

3. Berthonnaud E, Hilmi R, Dimnet J (2009) Personalized models of bones based on radiographic photogrammetry. Surg Radiol Anat 31:461-470

4. Brownhill JR, Furukawa K, Faber KJ, Johnson JA, King GJ (2006) Surgeon accuracy in the selection of the flexion-extension axis of the elbow: an in vitro study. J Should Elb Surg 15:451-456

5. Brownhill JR, King GJ, Johnson JA (2007) Morphologic analysis of the distal humerus with special interest in elbow implant sizing and alignment. J Should Elb Surg 16:S126-S132

6. Chaibi Y, Cresson T, Aubert B, Hausselle J, Neyret P, Hauger O, de Guise JA, Skalli W (2011) Fast 3D reconstruction of the lower limb using a parametric model and statistical inferences and clinical measurements calculation from biplanar X-rays. Comput Methods Biomech Biomed Engin (in press)

7. Cresson T, Godbout B, Branchaud D, Chav R, Gravel P, de Guise, JA (2008) Surface reconstruction from planar X-ray images using moving least squares. Conf Proc IEEE Eng Med Biol Soc 3967-3970

8. Deschênes S, Charron G, Beaudoin G, Labelle H, Dubois J, Miron MC, Parent S (2010) Diagnostic imaging of spinal deformities: reducing patients radiation dose with a new slotscanning X-ray imager. Spine 35:989-994 
9. Dubousset J, Charpak G, Dorion I, Skalli W, Lavaste F, de Guise JA (2005) A new 2D and 3D imaging approach to musculoskeletal physiology and pathology with low-dose radiation and the standing position: the EOS system. Bull Acad Natl Med 189:287-297

10. Ericson A, Arndt A, Stark A, Wretenberg P, Lundberg A (2003) Variation in the position and orientation of the elbow flexion axis. J Bone Joint Surg [Br] 85-B:538-544

11. Filippi S, Motyl B, Bandera C (2009) Comparing parametric solid modelling/reconfiguration, global shape modelling and free-form deformation for the generation of 3D digital models of femurs from X-rays images. Comput Methods Biomech Biomed Engin 12:101-108

12. Humbert L, de Guise JA, Aubert B, Godbout B, Skalli W (2009) $3 \mathrm{D}$ reconstruction of the spine from biplanar X-rays using parametric models based on transversal and longitudinal inferences. Med Eng Phys 31:681-687

13. London JT (1981) Kinematics of the elbow. J Bone Joint Surg 63:529-535
14. Mitton D, Deschenes S, Laporte S, Godbout B, Bertrand S, de Guise JA (2006) 3D reconstruction of the pelvis from bi-planar radiography. Comput Methods Biomech Biomed Engin 9:1-5

15. Morrey BF, Askew LJ, An KN EYSC (1981) A biomechanical study of normal functional elbow motion. J Bone Joint Surg 63:872-877

16. Pomero V, Mitton D, Laporte S, de Guise JA, Skalli W (2004) Fast accurate stereoradiographic 3D-reconstruction of the spine using a combined geometric and statistic model. Clin Biomech 19:240-247

17. Schuind F, O'Driscoll S, Korinek S, An KN, Morrey BF (1995) Loose-hinge total elbow arthroplasty. An experimental study of the effects of implant alignment on three-dimensional elbow kinematics. J Arthroplasty 10:670-678

18. Stokdijk M, Biegstraaten M, Ormel W, de Boer YA, Veeger HEJ, Rozing PM (2000) Determining the optimal flexion-extension axis of the elbow in vivo: a study of interobserver and intraobserver reliability. J Biomech 33:1139-1145 